\title{
Validation of a computer based system for assessing dietary intake
}

\author{
JAMES A LEVINE, ANGELA M MADDEN, MARSHA Y MORGAN
}

\begin{abstract}
Dietary intake was assessed in $\mathbf{5 0}$ patients in hospital by using a dietary history method and computer based system for data collection and standard food tables to calculate the composition of nutrients. The results were compared with those from a weighed assessment that was calculated by using both food tables and manufacturers' food analyses. The use of the food tables overestimated mean (SEM) individual nutrient intakes by between $2.5 \%(1.5 \%)$ and $15.5 \%(3.0 \%)$. The mean errors associated with the dietary history assessment varied from $-23 \%$ $(7 \cdot 8 \%)$ for fat intake to $+21.4 \%(8 \cdot 5 \%)$ for carbohydrate intake. Overall, $30 \%$ of the assessments of total nutrient intakes that were calculated using this method were within $-20 \%$ to $+20 \%$ of actual values; $18 \%$ were within $-10 \%$ to $+10 \%$. The mean errors associated with the computer based assessment varied from $-1.0 \%(4 \cdot 3 \%)$ for carbohydrate intake to $+8 \cdot 5 \%(3.4 \%)$ for protein intake. Overall, $56 \%$ of the assessments of total nutrient intakes were within $-20 \%$ to $+20 \%$ of actual intakes; $31 \%$ were within $-10 \%$ to $+10 \%$.

The computer based system provides an accurate, reproducible, convenient, and inexpensive method for assessing dietary intake.
\end{abstract}

\footnotetext{
Academic Department of Medicine and Department of Dietetics, Royal Free Hospital, London

JAMES A LEVINE, BSC, research fellow

ANGELA M MADDEN, BSC, senior dietitian, department of dietetics

MARSHA Y MORGAN, MRCP, senior research fellow and honorary senior lecturer

Correspondence to: Dr M Y Morgan, Medical Unit, Royal Free Hospital, London NW3 2QG.
}

\section{Introduction}

Information on dietary intake is often required in clinical practice. ${ }^{12}$ It is usually obtained by a dietitian based on an interview with the patient and sometimes the relatives. The nutrient composition of the diet is then determined using food tables such as McCance and Widdowson's The Composition of Foods which list, under numerative food codes, the nutrient compositions of many foods and dishes. ${ }^{3} \mathrm{~A}$ single food code corresponds to average values for several recipes and brands. The dietitian assigns a food code to each food item and estimates its weight from the description given by the patient. In large hospitals and in research units dietary assessment is facilitated by using a computer program containing the food tables: food codes and weights are entered and the composition of the diet is obtained on a printout. Otherwise the nutrient composition of the diet has to be calculated by hand.

There are several disadvantages in using the dietary history method for assessing food intake. Trained staff are required and the assessments are time consuming and tend to be inaccurate..$^{4.7}$ There are also inherent inaccuracies associated with the use of the food tables. ${ }^{8-10}$ Computers have several applications to medicine. ${ }^{11}$ It should be possible, using a computer based system, to improve the accuracy of dietary assessment by facilitating data collection. A patient operated, computer based system has been devised in our department to assess dietary intake and is the first of its kind.

The aim of this study was to validate this computer based system for assessing dietary intake in patients in hospital.

\section{Methods}

Fifty patients ( 25 men, 25 women), mean (SD) age 49.5 (12.8) years, who were admitted to general medical beds in this hospital were entered into the study. Patients were excluded if they were over 70 years of age, if they showed evidence of maldigestion or malabsorption, if they were unable to take or retain oral nourishment, or if they followed a restricted diet. Patients 
who had tumours of gastrointestinal origin or hepatic metastases and patients who had received chemotherapy in the three weeks before the study or in whom the gastrointestinal tract had been irradiated were also excluded.

\section{DIETARY INTAKE}

At the beginning of the study patients were given a list of 100 foods and beverages and asked to devise a three day menu for themselves. Mealtimes and frequencies could be specified.

Weighed assessment-For the next three days all foods and beverages were provided according to the patient's choice. Men were provided with a minimum of $11.7 \mathrm{MJ}$ and $60 \mathrm{~g}$ of protein and women with a minimum of $10.9 \mathrm{MJ}$ and $60 \mathrm{~g}$ of protein; snack foods and beverages were provided in addition. Recipes, meal presentation, and meal temperatures were standardised. Before presentation all items of food, plates, and cutlery were weighed to $\pm 0.01 \mathrm{~g}$ using the same scales. Food that remained after meals was dissected and each item reweighed. Plates and cutlery were reweighed before washing. The processing of all meals was undertaken by the same person (JAL). Patients were asked to consume only the foods provided, and relatives and ward staff knew of this restriction. Patients were carefully questioned each day to determine whether they had consumed foods other than those provided. The weight of each food item was calculated and food descriptions and weights were listed. Each food item was analysed by the manufacturers using standard food analysis techniques ${ }^{12}$; details of the energy, protein, fat, and carbohydrate content were provided. The dietary intakes of energy, protein, fat, and carbohydrate on each of the three study days were calculated, firstly, by using the manufacturers' food analyses and secondly, by assigning a code to each food item and using a computer program containing data from the food tables.

Dietary history method-On the second or third day of the study an experienced research dietitian assessed the patients' dietary intake in the previous 24 hours using a dietary history technique ${ }^{13}$ which conformed to the Guidelines for Taking Dietary Histories. ${ }^{14}$ The days on which the assessments were carried out were randomly assigned. Patients were asked to describe the kinds and quantities of foods that they had eaten. Food codes were assigned to each food item and an estimate made of the amounts consumed. The dietary intake was calculated using the food codes and food weights by a computer program containing the food tables. The duration of the interview and the time taken to calculate the dietary composition were recorded. All patients were assessed by the same dietitian (AMM).

Computer based system-On the second or third day of the study dietary intake was assessed using a portable, computer based system consisting of a $64 \mathrm{~K}$ microcomputer, a single disk drive, a $45 \mathrm{~cm} \times 30 \mathrm{~cm}$ television screen, and a printer. Fifteen keys on the computer keyboard were exposed for use; the keys were labelled $0-9$, Yes, No, 1/4, 1/2, and 3/4. The equipment cost £500. A computer program, which was designed and piloted at this hospital, was used to question the patient about food and beverage consumption during the preceding 24 hour period using a multiple cue system (table I). Check questions were included. Descriptions of all the food items that had been consumed throughout the 24 hour period and their approximate weights were obtained by providing lists of possible foods and standard household measures for selection. After a patient had been shown how to enter a single food all data were entered by the patient alone. Once the data were entered complex foods were converted by the computer program into constituent food items, and food codes and weights were assigned to each one. A printout of food codes and weights was obtained. The nutrient composition of the assessment was calculated by using the food codes and food weights by a separate computer program containing the food tables. The time taken to complete the computer based assessment was recorded.

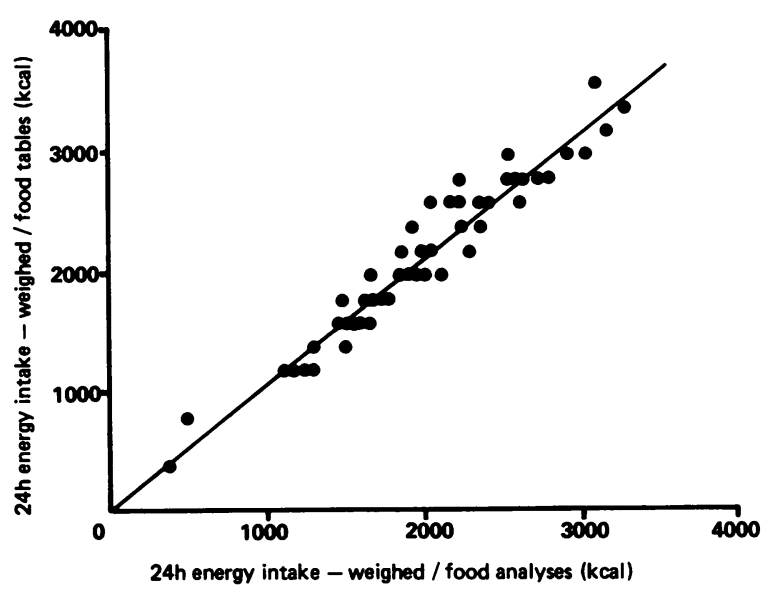

FIG 1-Relation between daily energy intake in 50 hospital inpaticnts from a weighed assessment that was analysed by using food table values $^{3}$ and manufacturers' food analyses. Conversion: Traditional units to $S I-1000 \mathrm{kcal} \approx 4 \cdot 18 \mathrm{MJ}$.

\section{DATA ANALYSIS}

Foods that were unaccounted for from the weighed assessments were estimated for each patient. Losses were expressed as a percentage of the total weight of food and as a percentage of daily energy intake.

The errors inherent in the use of food tables were determined by comparing the dietary intakes calculated by using the weighed assessment and the manufacturers' food analyses with the intakes calculated by using

TABLE $1-$ Sample dialogue of computer based system for assessing dietary intake

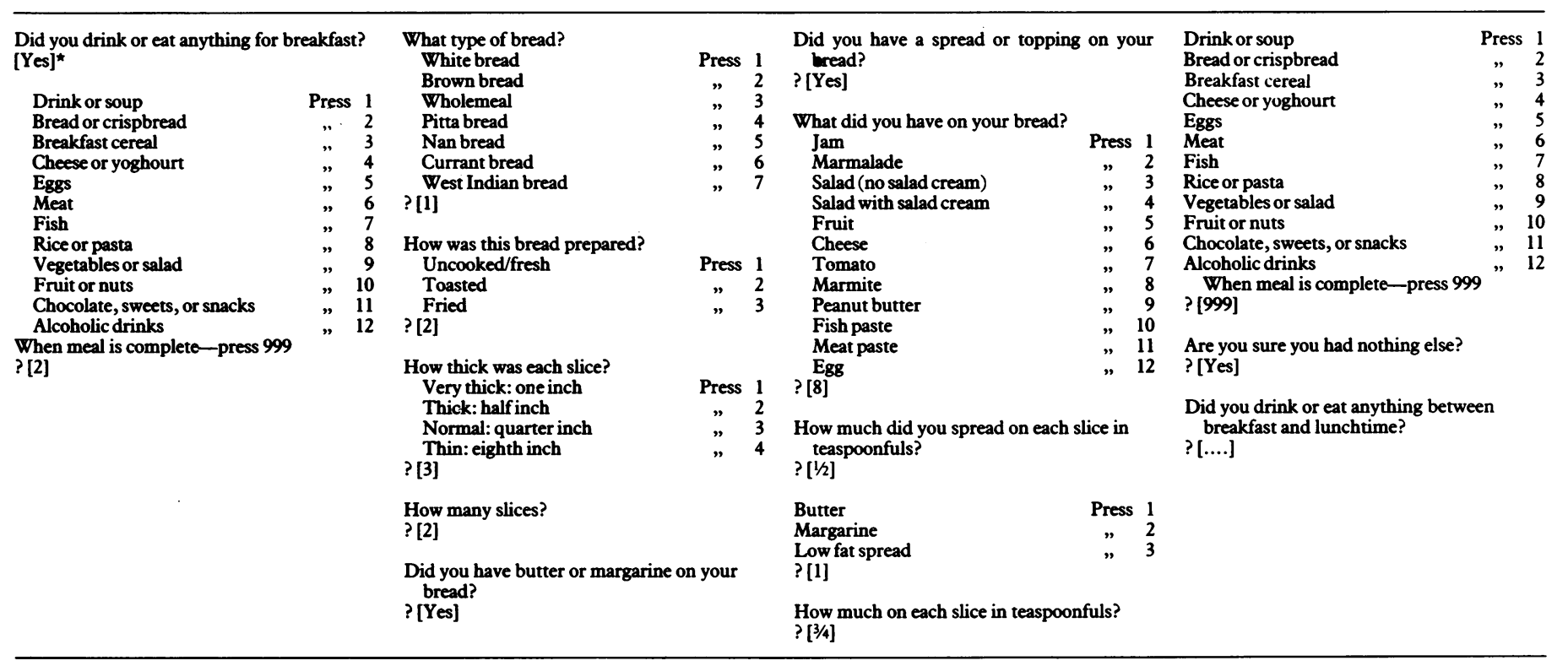

^Brackets show patient's response. 
TABLE II-Apparent and true errors associated with assessment of dietary intake using dietary history method and computer based system in 50 hospital inpatients. Values expressed as $\operatorname{mean}(S E M)$

\begin{tabular}{|c|c|c|c|c|c|c|c|c|c|c|c|c|c|}
\hline \multirow[b]{2}{*}{$\begin{array}{c}\text { Method } \\
\text { of } \\
\text { data } \\
\text { collection }\end{array}$} & \multirow[b]{2}{*}{$\begin{array}{c}\text { Method } \\
\text { for } \\
\text { data } \\
\text { processing }\end{array}$} & \multirow[b]{2}{*}{$\begin{array}{l}\text { Energy } \\
\text { (kcal) }\end{array}$} & \multicolumn{2}{|c|}{ Energy } & \multirow[b]{2}{*}{$\begin{array}{l}\text { Protein } \\
(\mathbf{g})\end{array}$} & \multicolumn{2}{|c|}{ Protein } & \multirow[b]{2}{*}{$\begin{array}{l}\text { Fat } \\
\text { (g) }\end{array}$} & \multicolumn{2}{|c|}{ Fat } & \multirow[b]{2}{*}{$\begin{array}{c}\text { Carbohydrate } \\
(\mathbf{g})\end{array}$} & \multicolumn{2}{|c|}{ Carbohydrate } \\
\hline & & & $\begin{array}{c}\text { Apparent } \\
\text { error } \\
(\%)\end{array}$ & $\begin{array}{l}\text { True } \\
\text { error } \\
(\%)\end{array}$ & & $\begin{array}{c}\text { Apparent } \\
\text { error } \\
(\%)\end{array}$ & $\begin{array}{l}\text { True } \\
\text { error } \\
(\%)\end{array}$ & & $\begin{array}{c}\text { Apparent } \\
\text { error } \\
(\%)\end{array}$ & $\begin{array}{l}\text { True } \\
\text { error } \\
(\%)\end{array}$ & & $\begin{array}{l}\text { Apparent } \\
\text { error } \\
(\%)\end{array}$ & $\begin{array}{l}\text { True } \\
\text { error } \\
(\%)\end{array}$ \\
\hline Weighed & Food analyses & $2019(90)$ & - & - & $68 \cdot 2(3 \cdot 4)$ & - & - & $102 \cdot 8(5 \cdot 3)$ & - & - & $219.9(10)$ & - & \\
\hline Weighed & Food tables & 2189 (97) & $=$ & $+9 \cdot 1(1.5)^{\star}$ & $73 \cdot 3(3 \cdot 7)$ & - & $+8 \cdot 0(1 \cdot 7)^{*}$ & $118.0(6.5)$ & - & $+15.5(3.0)^{*}$ & $223.5(10)$ & - & $+2.5(1.5)$ \\
\hline Dietary history & Food tables & 2110 (138) & $-1 \cdot 3(6 \cdot 2)$ & $-1 \cdot 1(6 \cdot 6)$ & $78 \cdot 0(5 \cdot 2)$ & $+9.9(7.2)$ & $+8 \cdot 2(7 \cdot 7)$ & $89 \cdot 4(7 \cdot 2)$ & $-17 \cdot 7(6 \cdot 8)^{* \star \star *}$ & $-23 \cdot 0(7 \cdot 8) \mathrm{Ht}$ & $259.4(17)$ & $+19 \cdot 6(8 \cdot 0)^{\star \star}$ & $+21.4(8.5) \dagger$ \\
\hline Computer system & Food tables & $2286(120)$ & $+4 \cdot 1(3 \cdot 4)$ & $+3 \cdot 7(4 \cdot 0)$ & $80 \cdot 9(5 \cdot 2)$ & $+8.5(3.4)$ & $+8.8(3.9)$ & $124 \cdot 2(9 \cdot 5)$ & $+7.2(6.5)$ & $+5 \cdot 6(7 \cdot 2)$ & $224 \cdot 4(13)$ & $0.0(3.9)$ & $-1 \cdot 0(4 \cdot 3)$ \\
\hline
\end{tabular}

Significance of the differences berween:

Weighed assessments calculated by using manufacturers' food analyses and food tables-* $0<0.001$

Dietary intakes assessed by the dietary history and computer based system and the essessments made using the weighed essessments calculated by using food tables-that is, the apparent errors- $* * p<0.05, * * * p<0.001$.

Dietary intakes assessed by dietary history method and computer based system and the assessments made by using the weighed assessmept calculated using manufacturers' food analyses after subtracting the food table errors-that is, the true errors-tp<0.05, $t \mathrm{tp}<0.001$

the weighed assessment and computer program containing the food tables. Differences were expressed as percentages.

For each patient the errors associated with the dietary history and computer based assessments of dietary intake were determined by comparing the intakes calculated by using these methods with those from the weighed assessments. Comparisons with the dietary intakes calculated by using the weighed assessment and the food tables determined the "apparent" error of the dietary history and computer based methods, as the errors inherent in the use of the food tables are included. Comparisons with the dietary intakes calculated by using the weighed assessment and the manufacturers' food analyses, after subtracting the food table errors, determined the "true" error of the dietary history and computer based methods of assessment. These errors were expressed as percentages and group means calculated from the individual data.

The degree to which energy values and combined nutrient values were overestimated or underestimated by the dietary history and computer based methods of assessment were determined by comparison with the weighed assessments that had been calculated using the manufacturers' food analyses after subtracting the food table errors. Estimates were expressed as percentages.

Data were analysed using Student's paired $t$ tests. Significance was defined as $\mathbf{p}<0 \cdot 05$.

\section{Results}

Food losses were of the order of $0 \cdot 1 \%$ of the total weight of food provided or $3 \%$ of daily energy intake. In the 50 patients the mean (SD) duration of the interview and the time taken to calculate the dietary composition was $20.4(8 \cdot 3)$ minutes and the mean time taken to complete the computer based assessment was $22 \cdot 1(4 \cdot 5)$ minutes. The difference was not significant. Patients had no difficulties in completing the dietary interview or the computer based assessment.

Dietary intakes determined from the weighed assessment differed significantly when calculated by using the food table values and the manufacturers' food analyses. The use of food tables for data processing resulted in overestimates in the mean (SEM) intakes of energy of $9 \cdot 1 \%$ $(1.5 \%)(p<0.001)$, protein $8.0 \%(1.7 \%)(p<0.001)$, fat $15.5 \%(3.0 \%)$ $(\mathrm{p}<0.001)$, and carbohydrate $2.5 \%(1.5 \%)$ (NS). (table II). There was a close relation, however, between the weighed assessments calculated by using the food tables and the manufacturers' food analyses (fig 1).

Differences were observed in the dietary intakes calculated by using the dietary history method and the weighed assessment. The mean (SEM) apparent errors associated with this method of data collection, determined by comparison with dietary intakes calculated by using the weighed assessment and food table values, varied from $-17 \cdot 7 \%(6 \cdot 8 \%)$ for fat intake $(p<0.001)$ to $+19.6 \%(8.0 \%)$ for carbohydrate intake $(p<0.05)$ (table II). The true errors associated with this method, determined by comparison with dietary intakes calculated by using the weighed assessment and manufacturers' food analyses after subtracting the food table errors, varied from $-23 \%(7 \cdot 8 \%)$ for fat intake $(p<0.001)$ to $+21 \cdot 4 \%(8 \cdot 5 \%)$ for carbohydrate intake $(\mathrm{p}<0.05)$ (table II; fig 2).

Differences were also observed in the dietary intakes calculated by using the computer based system and the weighed assessment. The mean (SEM) apparent errors associated with this method of data collection, determined by comparison with dietary intakes calculated by using the weighed assessment and food table values varied from $0 \%(3.9 \%)$ for carbohydrate intake (NS) to $+8 \cdot 5 \%(3 \cdot 4 \%)$ for protein intake (NS) (table II). The true errors associated with this method, determined by comparison with dietary intakes calculated by using the weighed assessment and manufacturers' food analyses after subtracting the food table errors varied from $-1 \cdot 0 \%(4 \cdot 3 \%)$ for

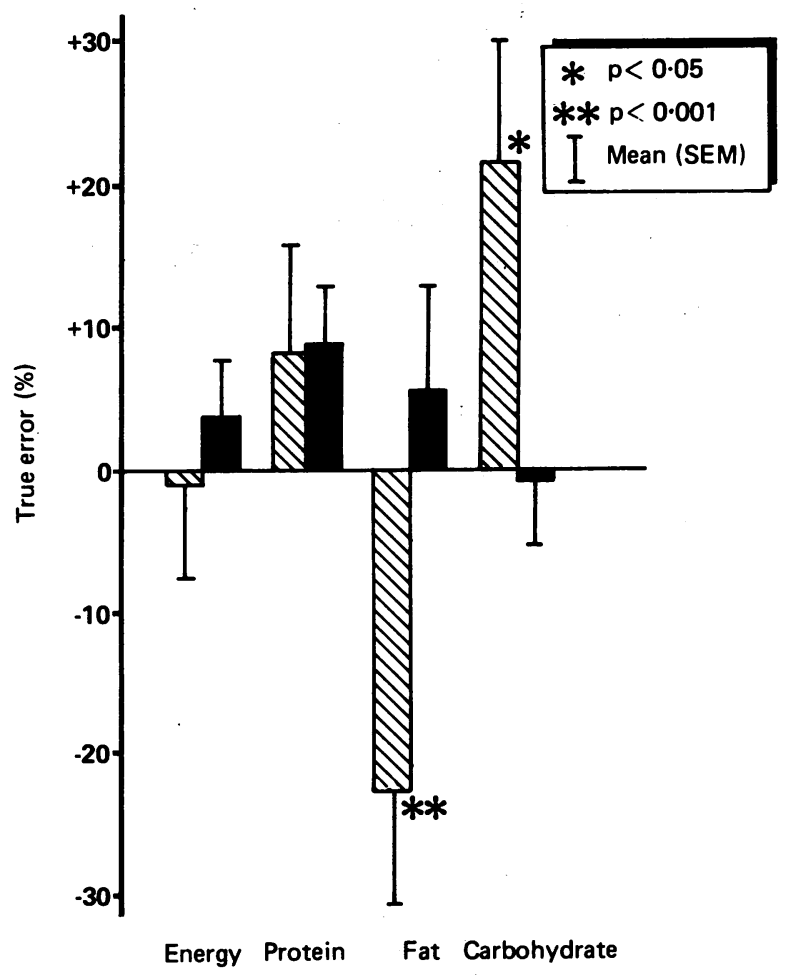

FIG 2-True errors made in assessing total nutrient intake in 50 hospital inpatients by using a dietary history method $(\mathbb{N})$ and a computer based system ( $\square$ ), determined by comparing intakes calculated by using these methods with intakes calculated from a weighed assessment and manufacturers' food analyses after subtracting the food table errors.

carbohydrate intake (NS) to $+8 \cdot 8 \%(3.9 \%)$ for protein intake (NS) (table II; fig 2).

Overall, $30 \%$ of the assessments of total nutrient intake calculated by using the dietary history method were within $-20 \%$ to $+20 \%$ of the values obtained from the weighed assessment and manufacturers' food analyses; $18 \%$ were within $-10 \%$ and $+10 \%$. Similar degrees of accuracy were observed in the assessments of total energy intake (fig $3 a$ ).

Overall, $56 \%$ of the assessments of total nutrient intake calculated by using the computer based system were within $-20 \%$ to $+20 \%$ of the values obtained from the weighed assessment and manufacturers' food analyses; $31 \%$ were within $-10 \%$ to $+10 \%$. Sixty per cent of the assessments of total energy intake calculated by using this system were within $-20 \%$ to $+20 \%$ of the actual values; $40 \%$ were within $-10 \%$ to $+10 \%$ (fig $3 b$ ).

\section{Discussion}

Information on dietary intake is required to assess nutrient state, to determine a baseline for therapeutic dietary regimens, and to monitor changes in body weight and intake of nutrients. This information is usually obtained by a dietitian during an interview 
with the patient and, if necessary, the relatives. These assessments are not accurate ${ }^{47}$ but may provide useful information when undertaken repeatedly in patients who act as their own controls.
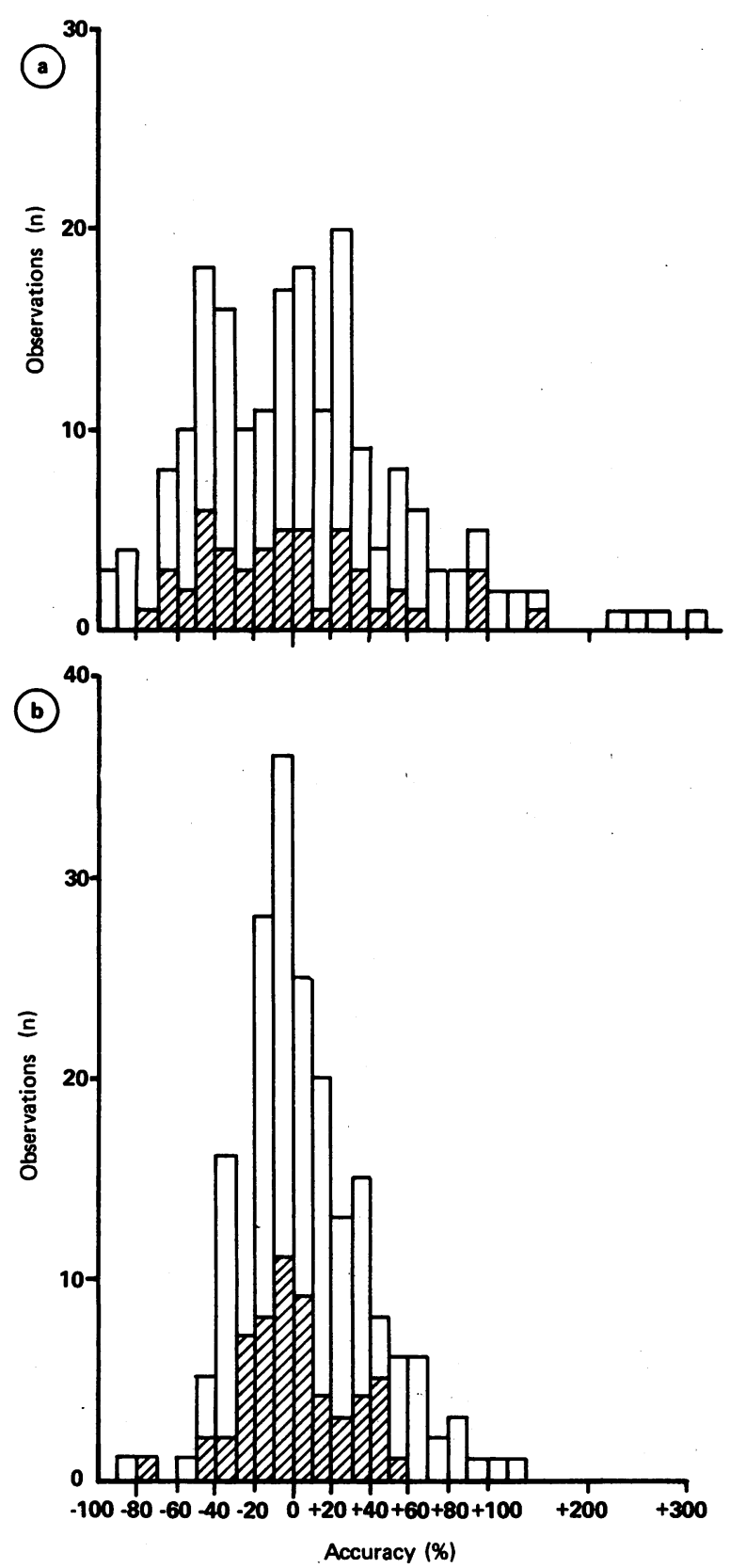

FIG 3-Number of observations on total daily nutrient intakes $(\square)$ and total daily energy intakes $(\mathbb{Z})$ assessed by $(a)$ a dietary history method and $(b)$ a computer based system which overestimated or underestimated the actual intake determined by a weighed assessment and manufacturers' food analyses.

This study was designed to validate the use of a computer based system for assessing dietary intake. As a preliminary step the errors that are inherent in the use of food table values for calculation of the nutrient composition of the diets were carefully assessed. Overall, the use of the food tables significantly overestimated nutrient intakes by $3 \%$ to $16 \%$, and this source of error was taken into account when determining the accuracy of dietary intakes assessed by the dietary history method and the computer based system. Food losses amounted to only $3 \%$ of total energy, which compares favourably with the losses reported in other studies. ${ }^{15}$ Several potential sources of error could still be identified, however. Firstly, assessment of intake over three days may not be representative, although recent evidence suggests that three days should be sufficient. ${ }^{16}$ Secondly, the diet chosen by the patient might not reflect his or her normal diet, although care was taken to provide a variety of popular foods for menu selection. Finally, food composition might vary over time, and the manufacturers' food analyses might be inaccurate. The errors from these sources were assumed to be small.

The results of the study show that the assessments of dietary intake using the computer based system were more accurate than those using the dietary history method, although both assessments took about 20 minutes and used similar formats. Overall, $56 \%$ of the computer assessments of total nutrient intakes were within $-20 \%$ to $+20 \%$ of actual values compared with only $30 \%$ of the dietary history assessments; $31 \%$ of the computer assessments were within $-10 \%$ to $+10 \%$ of actual values compared with only $18 \%$ of the dietary history assessments. The dietary history assessments in this study are probably more accurate than those obtained ordinarily, as the dietitian was experienced, had only a few foods to deal with, and knew that her performance was being monitored.

There are several disadvantages in using a dietary history method for assessing intake apart from its inaccuracy. Trained staff are required, the assessments may be time consuming, and the assessments are not standardised and cannot therefore be sasily compared. There are, however, some advantages. During the interview valuable information may be obtained about food preferences, cooking methods, and available finance. In addition, the dietitian can form a relationship with the patient, and there is the opportunity for patient education.

The advantages of a computer based system for assessing dietary intake apart from its accuracy are: no trained staff are required for data collection, the assessments are standardised and hence reproducible, and the system is portable and operated by the patient. The computer based system as described here provides an accurate, reproducible, convenient, and inexpensive method for assessing dietary intake.

We thank Professor N McIntyre, Dr O Epstein, Dr E Boeson, and Dr C Symons for allowing us to study patients under their care and Miss $\mathbf{C}$ Bateman, district dietitian, for helpful discussion and advice. Heinz, McCain and Walls kindly undertook the food analyses.

JAL is in receipt of an Elmore Medical Research Studentship from the University of Cambridge and a grant from the Sir John Cass Foundation.

\section{References}

1 Marr JW. Individual dietary surveys: purposes and methods. World Rev Nutr Diet 1971;13: 105-64.

2 Butterworth CE Jr, Weinsier RL. Malnutrition in hospitalized patients: assessment and treatment. In: Goodhart RS, Shils ME, eds. Modern nutrition in health and disease. 6th ed. Philadelphia: Lea and Febiger, 1978:667-84.

3 Paul AA, Southgate DAT. McCance and Widdowson's the composition of foods. 4th ed. London: HMSO, 1978.

4 Madden JP, Goodman SJ, Guthrie HA. Validity of the 24-hr recall. Analysis of data obtained from elderly subjects. I Am Diet Assoc 1976;68:143-7.

5 Todd KS, Hudes M, Calloway DH. Food intake measurement: problems and approaches. Am $\mathcal{f}$ Clin Nutr 1983;37:139-46.

6 Linusson EEI, Sanjur D, Erickson EG. Validating the 24 hour recall method as a dietary survey tool. Arch Latinoam Nutr 1974;24:277-94.

7 Young CM, Chalmers FW, Church HN, et al. Comparison of dietary study methods; dietary Young CM, Chalmers FW, Church HN, et al. Comparis
history vs 7-day-record. I Am Diet Assoc 1952;28:124-8.

history vs 7-day-record. $\mathcal{A}$ Am Diet Assoc 1952;28:124-8.
8 Widdowson EM, McCance RA. Food tables: their scope and limitations. Lancet 1943;i:230-2.

8 Widdowson EM, McCance RA. Food tables: their scope and limitations. Lancet 1943;i:230-2.
9 Black AE, Ravenscroft C, Paul AA. Footnotes to food tables: 1 . Differences in nutrient intakes Black AE, Ravenscroft C, Paul AA. Footnotes to fod tables: 1 . Differences in nutrient intakes
of dietitians as calculated from the DHSS food tables and the fourth edition of MCCance and of dietitians as calculated from the DHSS food tables and the fourth edition

10 Walberg SM, Adams WS. Calculated and determined values in constant diets. $f$ Am Diet Assoc 1965;47:37-43.

11 Slack WV, Hicks GP, Reed CE, Van Cura LJ. A computer-based medical-history system. N Engl J Med 1966;274:194-8.

12 Foltz AK, Yeransian JA, Sloman KG. Food. Anal Chem 1977;49:194R-220R.

13 Burke BS. Dietary history as a tool in research. $f$ Am Diet Assoc 1947;23:1041-6.

14 British Dietetic Association. Gridelines for taking dietary histories. London: BDA, 1979.

15 Eppright ES, Patton MB, Marlatt AL, Hathaway ML. Dietary study methods: some problems in collecting dietary information about groups of children. $\mathcal{A}$ Am Diet Assoc 1952;28:43-8.

16 Marr JW, Heady JA. Within- and between-person variation in dietary surveys: number of days meeded to classify individuals. Hum Nutr Appl Nutr 1986;40A:347-64.

(Accepted 23 April 1987) 